\title{
Predicting the Surgical Site Infections in Patients Undergoing Lumbar Internal Fixation Surgery: A New Predictive Nomogram is Evelopmenting and Assessmenting
}

\section{Tianyou Chen}

Guangxi Medical University

Chong Liu

The First Affiliated Hospital of Guangxi Medical University

Zide Zhang

Guangxi Medical University

Tuo Liang

Guangxi Medical University

Jiarui Chen

Guangxi Medical University

Jie Jiang

Guangxi Medical University

Hao Li

Guangxi Medical University

Hao Guo

Guangxi Medical University

wuhua chen

Guangxi Medical University

zhen ye

Guangxi Medical University

yuanlin yao

Guangxi Medical University

shian liao

Guangxi Medical University

xinli zhan ( $\nabla$ zhanxinli@stu.gxmu.edu.cn )

Guangxi Medical University

Research Article 
Keywords: lumbar Internal Fixation Surgery, SSI, predictors, nomogram, validation

Posted Date: January 31st, 2022

DOI: https://doi.org/10.21203/rs.3.rs-1156352/v1

License: (c) (1) This work is licensed under a Creative Commons Attribution 4.0 International License. Read Full License 


\section{Abstract \\ Purpose}

The purpose of this research is to develop and validate a nomogram of the risk of surgical site infections in Patients Undergoing lumbar Internal Fixation Surgery.

\section{Patients and methods:}

We had collected a total of 1327 patients with lumbar internal fixation surgery, 1273 patients were normal lumbar fixation group and 54 patients in the surgical site infections group. Patients are divided into two echelons of testing and verification, and R software is used as the only statistical analysis. In the training tests, first, single factor logistic regression analysis was used to select potential predictors with significant $p$-values. Then multivariate logistic regression analysis is used to filter out the predictors which we need. A nomogram was constructed using the coefficients of variable provided by Multivariate logistic regression analysis, the calibration and clinical applicability of the predictive model are evaluated by using the $\mathrm{C}$ index, calibration curve, and decision curve. In addition, we use internal verification tests to verify the built model.

\section{Results}

This unprecedented nomogram of SSI risk for lumbar Internal Fixation Surgery includes modic status, glucose, $\mathrm{Hb}, \mathrm{ESR}$, blood transfusion, sebum thickness. The model shows a good degree of discrimination, with a C index of 0.975 (95\% confidence interval: $0.964,0.987)$ and good alignment. The decision curve analysis showed that the SSI nomogram is clinically meaningful when the $1 \%$ probability threshold of the normal group is used to determine the intervention. The C-index of the validation test was $0.981(95 \%$ confidence interval: 0. 957, 1.005).

\section{Conclusion}

This novel SSI prediction nomogram combines Modic status, glucose, Hb, ESR, blood transfusion, sebum thickness, and can be easily used for individualized SSI probability prediction in lumbar Internal Fixation Surgery patients.

\section{Introduction}

Surgical site infection (SSI) is defined as infections occurring up to 30 days after surgery (or up to one year after surgery in patients receiving implants) and affecting either the incision or deep tissue at the operation site. Because of SSI is associated with a large number of morbidities and leads to a significant increase in hospitalization costs, although improvements in prevention and drug development have 
reduced their percentage, they remain an important clinical issue[1]. Lumbar Internal Fixation Surgery is an established treatment for a range of spinal disorders including: degenerative pathologies, trauma, and neoplasia. Besides, under the consensus of rapid recovery, early identification of the risk factors of postoperative SSI and prevention is more conducive to the recovery of patients after spinal surgery. Previous researches have shown that diabetes, fusion segments, erythrocyte sedimentation rate, protein, whether to use antibiotics preventively, and etc, are directly related to the occurrence of postoperative wound infections[2].

In China, there are many patients who need lumbar internal fixation every year, and the related complications should not be underestimated. The occurrence of complications after surgery often brings additional burdens to patients, including economic, psychological, satisfaction, etc. Among them, Surgical site infection is one of the most serious complications following spinal surgery during the early postoperative stage, and has always been one of the focuses of spine doctors[3]. Many risk factors related to the occurrence of SSI have been found in previous studies, but there was no predictive model that can comprehensively assess the probability of occurrence of SSI before surgery[4-6]. Thus, the purpose of this research is to develop and validate a nomogram of the risk of lumbar postoperative surgery site infection by using the same characteristics.

\section{Patients And Methods}

\subsection{Patients and Research Design.}

This study was approved by the institutional review board of our hospital (Approval No. 2021(KY-E-223)). A retrospective study was established, and the subjects were patients who undergoing lumbar internal fixation surgery in single center from May 2016 to February 2021. The data which we collected showed that there were 54 cases in the surgical site infection group and 1273 cases in the lumbar normal fixation group.

The US Centers for Disease Control and Prevention Guidelines for the Prevention of SSI (2018 Edition) are used as the diagnostic criteria for postoperative SSI[7]. Superficial SSI often manifests as redness, tenderness, swelling, fever, and pain in the area. It refers to infections that happen in the skin and subcutaneous tissues only within 30 days after surgery. The signs and symptoms of deep SSI are usually fever, pain, tenderness, continuous drainage or bleeding from wounds, abscesses or nodules, needing surgical debridement or even implant removal. Usually refers to an infection involving the muscle and fascia that occurred within 1 year (the implant remains in place). Determined the SSI case by looking at the information registered on the patient's medical record to determine the signs or symptoms recorded during the hospitalization.

The inclusion criteria for the surgical site infections group include.

(a) Patients who require lumbar internal fixation surgery to be admitted to the hospital from May 2016 to February 2021. 
(b) Posterior lumbar internal fixation surgery, including lumbar spondylolisthesis, lumbar disc herniation, lumbar spinal stenosis, lumbar spinal tumor, lumbar scoliosis correction, etc.

(c) Before the operation, the skin of the operation area is intact, without ulceration, suppuration, ulcers, plaques, etc.

(d) Deep tissue necrosis in the operation area, accompanied by chills, high fever, swelling of the operation area, drainage tube drainage of purulent secretions, bacterial culture (+).

(e) For the first discovery after lumbar internal fixation, and the first debridement for the postoperative incision.

The exclusion criteria for the surgical site infections group included.

(a) Patients who excluded from inclusion criteria.

(b) The patient stimulates the incision due to irresistible factors, such as immersion, contamination, premature stitch removal, and the use of toxic liquids.

(c)Long-segment scoliosis that is not predominantly lumbar curvature, lumbar malignant tumor invasion, lumbar tuberculosis, preoperative skin ulceration and inflammation in the lumbar spine surgery area.

(d) Patients whom clinical and imaging data were imperfect.

The inclusion criteria for the normal group of lumbar spine fixation include.

Patients who require lumbar internal fixation surgery to be admitted to the hospital from May 2016 to February 2021, Including lumbar degenerative diseases, such as lumbar disc herniation, lumbar spinal stenosis, degenerative scoliosis, etc. As well as internal fixation of lumbar fractures, lumbar spinal tumors, etc.

The exclusion criteria for the normal group receiving lumbar spine fixation include.

(a) Patients who excluded from inclusion criteria.

(b) Patients whom clinical and imaging data were imperfect.

\subsection{Evaluation Variables.}

Gender, age, diabetes, modic, ASA, additional antibiotics, operation time, number of vertebral bodies spanned, number of screws, anesthesia time, glucose, WBC, Hb, PLT, albumin, ESR, blood transfusion sebum thickness and skin to lamina thickness of the patients were collected from the His medical system at our Hospital. The indicators collected using the hospital imaging system, including the number of vertebrae spanned and the number of screws. 


\subsection{Statistical Analysis}

The R software(Version 3.6.0: https://www.R-project.org/) was used for statistical analysis. The following steps were used to build the prediction model and select the most appropriate SSI predictors. First, Single factor logistic regression analysis was used to select potential predictors with significant p-values. Then multivariate logistic regression analysis is used to filter out the predictors which we need. Fanally, a nomogram was constructed using the coefficients of variable provided by Multivariate logistic regression analysis.

Two-sidedness as the main feature of statistical significance level. By introducing and analyzing the statistical significance level of all selected features, the SSI risk prediction model were developed by applying statistically significant predictors and potential features. The calibration of SSI was evaluated by constructing a calibration curve. measuring Harrell $C$ index were to quantify the performance of the SSI fault nomogram. By quantifying the net income of the spinal instrument group under different threshold probabilities, the decision curve analysis is performed to determine the clinical applicability of the SSI nomogram. In the calculation method of net benefit, the proportion of all false positive patients is not included in the proportion of true positive patients, and the relative harm of giving up intervention is weighed against the negative consequences of unnecessary intervention. The readiness of the SSI risk nomogram we constructed was evaluated by using internal verification tests.

\section{Results}

\subsection{Patient Characteristics.}

There were 54 patients in the SSI group and 1273 patients in the normal lumbar fixation group. In the experimental group and the validation group, the baseline characteristics of all study patients (SSI and normal groups) are shown in Table 1 and 2 respectively. Typical cases of surgery site infection after lumbar internal fixation surgery were shown in Figure 1. 
Table 1

Clinical characteristics of patients with lumbar Internal Fixation Surgery patients in training test.

\begin{tabular}{|c|c|c|c|c|}
\hline Characteristics & $\begin{array}{l}\text { Yes } \\
(\mathrm{N}=42)\end{array}$ & $\begin{array}{l}\text { No } \\
(N=1020)\end{array}$ & $\begin{array}{l}\mathrm{P} \text { - } \\
\text { value }\end{array}$ & $\begin{array}{l}\text { TRUE } \\
(\mathrm{N}=1062)\end{array}$ \\
\hline Gender & & & 0.117 & \\
\hline Female & $28(66.7 \%)$ & $542(53.1 \%)$ & & $570(53.7 \%)$ \\
\hline Male & $14(33.3 \%)$ & $478(46.9 \%)$ & & $492(46.3 \%)$ \\
\hline Age & & & 0.391 & \\
\hline Mean (SD) & $58.4(13.9)$ & $56.5(11.2)$ & & $56.6(11.3)$ \\
\hline Median [Min, Max] & $\begin{array}{l}60.0[21.0, \\
80.0]\end{array}$ & $\begin{array}{l}56.0[12.0, \\
87.0]\end{array}$ & & $\begin{array}{l}56.0[12.0, \\
87.0]\end{array}$ \\
\hline Diabetes & & & 1 & \\
\hline No & 38 (90.5\%) & $922(90.4 \%)$ & & $960(90.4 \%)$ \\
\hline Yes & $4(9.5 \%)$ & $98(9.6 \%)$ & & $102(9.6 \%)$ \\
\hline Modic & & & $<0.001$ & \\
\hline A & $0(0 \%)$ & $868(85.1 \%)$ & & $868(81.7 \%)$ \\
\hline B & $15(35.7 \%)$ & $109(10.7 \%)$ & & $124(11.7 \%)$ \\
\hline C & $27(64.3 \%)$ & $43(4.2 \%)$ & & $70(6.6 \%)$ \\
\hline ASA & & & 0.125 & \\
\hline A & $5(11.9 \%)$ & $54(5.3 \%)$ & & $59(5.6 \%)$ \\
\hline B & $29(69.0 \%)$ & $812(79.6 \%)$ & & $841(79.2 \%)$ \\
\hline C & $8(19.0 \%)$ & $154(15.1 \%)$ & & $162(15.3 \%)$ \\
\hline Antibiotics & & & 0.005 & \\
\hline No & $21(50.0 \%)$ & $728(71.4 \%)$ & & 749 (70.5\%) \\
\hline Yes & $21(50.0 \%)$ & $292(28.6 \%)$ & & $313(29.5 \%)$ \\
\hline OP_times & & & 0.471 & \\
\hline Mean (SD) & $103(64.3)$ & $96.1(49.4)$ & & $96.4(50.1)$ \\
\hline Median [Min, Max] & $\begin{array}{l}95.4[14.3, \\
313]\end{array}$ & $83.5[2.00,339]$ & & $84.0[2.00,339]$ \\
\hline
\end{tabular}

Abbreviations: ASA: American Society of Anesthesiologists; OP times: operation times; AT: Anesthesia time; ESR: erythrocyte sedimentation rate; 


\begin{tabular}{|c|c|c|c|c|}
\hline Characteristics & $\begin{array}{l}\text { Yes } \\
(\mathrm{N}=42)\end{array}$ & $\begin{array}{l}\text { No } \\
(N=1020)\end{array}$ & $\begin{array}{l}\mathrm{P}- \\
\text { value }\end{array}$ & $\begin{array}{l}\text { TRUE } \\
(\mathrm{N}=1062)\end{array}$ \\
\hline $\begin{array}{l}\text { Number of vertebral bodies } \\
\text { spanned }\end{array}$ & & & 0.167 & \\
\hline Mean (SD) & $2.40(2.39)$ & $1.88(0.883)$ & & $1.90(0.990)$ \\
\hline Median [Min, Max] & $\begin{array}{l}2.00[1.00 \\
12.0]\end{array}$ & $\begin{array}{l}2.00[1.00 \\
6.00]\end{array}$ & & $\begin{array}{l}2.00[1.00 \\
12.0]\end{array}$ \\
\hline Number of screws & & & 0.034 & \\
\hline Mean (SD) & $6.26(3.41)$ & $5.10(1.59)$ & & $5.15(1.71)$ \\
\hline Median [Min, Max] & $\begin{array}{l}6.00[1.00 \\
20.0]\end{array}$ & $\begin{array}{l}4.00[2.00 \\
12.0]\end{array}$ & & $\begin{array}{l}4.00[1.00 \\
20.0]\end{array}$ \\
\hline AT & & & 0.105 & \\
\hline Mean (SD) & $97.1(67.5)$ & $115(54.9)$ & & $114(55.5)$ \\
\hline Median [Min, Max] & $\begin{array}{l}80.0[10.0 \\
340]\end{array}$ & $100[20.0,379]$ & & $100[10.0,379]$ \\
\hline Glucose & & & 0.032 & \\
\hline Mean (SD) & $6.46(2.33)$ & $5.65(2.05)$ & & $5.68(2.07)$ \\
\hline Median [Min, Max] & $\begin{array}{l}5.38[3.30 \\
11.5]\end{array}$ & $\begin{array}{l}5.07[2.90 \\
22.0]\end{array}$ & & $\begin{array}{l}5.07[2.90 \\
22.0]\end{array}$ \\
\hline WBC & & & 0.018 & \\
\hline Mean (SD) & $10.0(4.00)$ & $8.47(3.48)$ & & $8.53(3.52)$ \\
\hline Median [Min, Max] & $\begin{array}{l}9.02[3.93, \\
23.0]\end{array}$ & $\begin{array}{l}7.50[3.01 \\
25.8]\end{array}$ & & $\begin{array}{l}7.56[3.01 \\
25.8]\end{array}$ \\
\hline $\mathrm{Hb}$ & & & $<0.001$ & \\
\hline Mean (SD) & $105(19.1)$ & $126(20.1)$ & & $126(20.5)$ \\
\hline Median [Min, Max] & $104[67.8,143]$ & $128[50.0,178]$ & & $127[50.0,178]$ \\
\hline PLT & & & 0.760 & \\
\hline Mean (SD) & $262(118)$ & $257(97.6)$ & & $257(98.4)$ \\
\hline Median [Min, Max] & $225[75.1,518]$ & $\begin{array}{l}247[26.7 \\
2250]\end{array}$ & & $\begin{array}{l}246[26.7 \\
2250]\end{array}$ \\
\hline Albumin & & & $<0.001$ & \\
\hline
\end{tabular}

Abbreviations: ASA: American Society of Anesthesiologists; OP times: operation times; AT: Anesthesia time; ESR: erythrocyte sedimentation rate; 


\begin{tabular}{|c|c|c|c|c|}
\hline Characteristics & $\begin{array}{l}\text { Yes } \\
(N=42)\end{array}$ & $\begin{array}{l}\text { No } \\
(N=1020)\end{array}$ & $\begin{array}{l}P \text { - } \\
\text { value }\end{array}$ & $\begin{array}{l}\text { TRUE } \\
(\mathrm{N}=1062)\end{array}$ \\
\hline Mean (SD) & $36.0(6.23)$ & $40.1(4.90)$ & & $40.0(5.02)$ \\
\hline Median [Min, Max] & $\begin{array}{l}35.9[24.4, \\
47.5]\end{array}$ & $\begin{array}{l}40.1[22.1 \\
55.1]\end{array}$ & & $\begin{array}{l}40.0[22.1 \\
55.1]\end{array}$ \\
\hline ESR & & & $<0.001$ & \\
\hline Mean (SD) & $34.2(26.9)$ & $18.2(17.7)$ & & $18.9(18.4)$ \\
\hline Median [Min, Max] & $\begin{array}{l}23.0[5.00, \\
103]\end{array}$ & $13.0[1.00,102]$ & & $13.0[1.00,103]$ \\
\hline Blood transfusion & & & $<0.001$ & \\
\hline No & $27(64.3 \%)$ & $933(91.5 \%)$ & & $960(90.4 \%)$ \\
\hline Yes & $15(35.7 \%)$ & $87(8.5 \%)$ & & $102(9.6 \%)$ \\
\hline Sebum thickness & & & 0.001 & \\
\hline Mean (SD) & $12.7(9.04)$ & $7.87(4.02)$ & & $8.06(4.42)$ \\
\hline Median [Min, Max] & $\begin{array}{l}10.9[4.12, \\
41.3]\end{array}$ & $\begin{array}{l}7.12[1.45, \\
48.9]\end{array}$ & & $\begin{array}{l}7.22[1.45, \\
48.9]\end{array}$ \\
\hline Skin to lamina thickness & & & 0.302 & \\
\hline Mean (SD) & $49.4(12.2)$ & $47.4(9.70)$ & & $47.5(9.81)$ \\
\hline Median [Min, Max] & $\begin{array}{l}47.4[28.7, \\
78.1]\end{array}$ & $\begin{array}{l}46.7[2.74, \\
88.3]\end{array}$ & & $\begin{array}{l}\text { 46.7 [2.74, } \\
88.3]\end{array}$ \\
\hline
\end{tabular}


Table 2

Clinical characteristics of patients with lumbar Internal Fixation Surgery patients in validation test.

\begin{tabular}{|c|c|c|c|c|}
\hline Characteristics & $\begin{array}{l}\text { Yes } \\
(\mathrm{N}=12)\end{array}$ & $\begin{array}{l}\text { No } \\
(\mathrm{N}=253)\end{array}$ & $\begin{array}{l}\mathrm{P}- \\
\text { value }\end{array}$ & $\begin{array}{l}\text { TRUE } \\
(\mathrm{N}=265)\end{array}$ \\
\hline Gender & & & 0.124 & \\
\hline Female & $10(83.3 \%)$ & $143(56.5 \%)$ & & $153(57.7 \%)$ \\
\hline Male & $2(16.7 \%)$ & $110(43.5 \%)$ & & $112(42.3 \%)$ \\
\hline Age & & & 0.134 & \\
\hline Mean (SD) & $61.2(10.6)$ & $56.1(10.8)$ & & $56.4(10.8)$ \\
\hline Median [Min, Max] & $\begin{array}{l}62.0[35.0, \\
78.0]\end{array}$ & $\begin{array}{l}57.0[26.0, \\
80.0]\end{array}$ & & $\begin{array}{l}57.0[26.0, \\
80.0]\end{array}$ \\
\hline Diabetes & & & 1 & \\
\hline No & $11(91.7 \%)$ & $233(92.1 \%)$ & & $244(92.1 \%)$ \\
\hline Yes & $1(8.3 \%)$ & $20(7.9 \%)$ & & $21(7.9 \%)$ \\
\hline Modic & & & $<0.001$ & \\
\hline A & $0(0 \%)$ & $218(86.2 \%)$ & & $218(82.3 \%)$ \\
\hline B & $3(25.0 \%)$ & $26(10.3 \%)$ & & $29(10.9 \%)$ \\
\hline $\mathrm{C}$ & $9(75.0 \%)$ & $9(3.6 \%)$ & & $18(6.8 \%)$ \\
\hline ASA & & & 0.634 & \\
\hline A & $0(0 \%)$ & $11(4.3 \%)$ & & $11(4.2 \%)$ \\
\hline B & $9(75.0 \%)$ & $198(78.3 \%)$ & & $207(78.1 \%)$ \\
\hline C & $3(25.0 \%)$ & $44(17.4 \%)$ & & $47(17.7 \%)$ \\
\hline Antibiotics & & & 1 & \\
\hline No & $9(75.0 \%)$ & $182(71.9 \%)$ & & $191(72.1 \%)$ \\
\hline Yes & $3(25.0 \%)$ & $71(28.1 \%)$ & & $74(27.9 \%)$ \\
\hline OP times & & & 0.665 & \\
\hline Mean (SD) & $87.3(55.7)$ & $94.6(45.7)$ & & $94.3(46.1)$ \\
\hline Median [Min, Max] & $\begin{array}{l}75.7 \text { [28.0, } \\
195]\end{array}$ & $86.0[23.0,269]$ & & $85.0[23.0,269]$ \\
\hline
\end{tabular}

Abbreviations: ASA: American Society of Anesthesiologists; OP times: operation times; AT: Anesthesia time; ESR: erythrocyte sedimentation rate; 


\begin{tabular}{|c|c|c|c|c|}
\hline Characteristics & $\begin{array}{l}\text { Yes } \\
(\mathrm{N}=12)\end{array}$ & $\begin{array}{l}\text { No } \\
(N=253)\end{array}$ & $\begin{array}{l}\mathrm{P}- \\
\text { value }\end{array}$ & $\begin{array}{l}\text { TRUE } \\
(\mathrm{N}=265)\end{array}$ \\
\hline $\begin{array}{l}\text { Number of vertebral bodies } \\
\text { spanned }\end{array}$ & & & 0.142 & \\
\hline Mean (SD) & $2.58(1.68)$ & $1.81(0.782)$ & & $1.85(0.853)$ \\
\hline Median [Min, Max] & $\begin{array}{l}2.00[1.00 \\
6.00]\end{array}$ & $\begin{array}{l}2.00[1.00 \\
4.00]\end{array}$ & & $\begin{array}{l}2.00[1.00 \\
6.00]\end{array}$ \\
\hline Number of screws & & & 0.173 & \\
\hline Mean (SD) & $6.25(3.02)$ & $4.98(1.47)$ & & $5.03(1.58)$ \\
\hline Median [Min, Max] & $\begin{array}{l}5.00[3.00, \\
12.0]\end{array}$ & $\begin{array}{l}4.00[2.00, \\
10.0]\end{array}$ & & $\begin{array}{l}4.00[2.00, \\
12.0]\end{array}$ \\
\hline AT & & & 0.14 & \\
\hline Mean (SD) & 84.7 (63.2) & $114(50.4)$ & & $113(51.2)$ \\
\hline Median [Min, Max] & $\begin{array}{l}60.0[26.7, \\
200]\end{array}$ & $105[26.7,309]$ & & $101[26.7,309]$ \\
\hline Glucose & & & 0.091 & \\
\hline Mean (SD) & $6.20(1.30)$ & $5.48(1.77)$ & & $5.51(1.75)$ \\
\hline Median [Min, Max] & $\begin{array}{l}6.26[4.60, \\
8.32]\end{array}$ & $\begin{array}{l}5.01[3.28, \\
18.0]\end{array}$ & & $\begin{array}{l}5.04[3.28, \\
18.0]\end{array}$ \\
\hline WBC & & & 0.868 & \\
\hline Mean (SD) & $8.50(3.04)$ & $8.35(3.25)$ & & $8.35(3.23)$ \\
\hline Median [Min, Max] & $\begin{array}{l}9.29[4.49 \\
13.7]\end{array}$ & $\begin{array}{l}7.43[3.30 \\
18.2]\end{array}$ & & $\begin{array}{l}7.43[3.30 \\
18.2]\end{array}$ \\
\hline $\mathrm{Hb}$ & & & 0.049 & \\
\hline Mean (SD) & $113(21.3)$ & $127(18.8)$ & & $126(19.1)$ \\
\hline Median [Min, Max] & $122[68.0,132]$ & $128[71.8,175]$ & & $127[68.0,175]$ \\
\hline PLT & & & 0.112 & \\
\hline Mean (SD) & 217 (86.9) & $262(102)$ & & $260(102)$ \\
\hline Median [Min, Max] & $224[45.8,314]$ & $\begin{array}{l}250[92.0 \\
1160]\end{array}$ & & $\begin{array}{l}250[45.8 \\
1160]\end{array}$ \\
\hline Albumin & & & 0.355 & \\
\hline
\end{tabular}

Abbreviations: ASA: American Society of Anesthesiologists; OP times: operation times; AT: Anesthesia time; ESR: erythrocyte sedimentation rate; 


\begin{tabular}{|c|c|c|c|c|}
\hline Characteristics & $\begin{array}{l}\text { Yes } \\
(\mathrm{N}=12)\end{array}$ & $\begin{array}{l}\text { No } \\
(N=253)\end{array}$ & $\begin{array}{l}P \text { - } \\
\text { value }\end{array}$ & $\begin{array}{l}\text { TRUE } \\
(\mathrm{N}=265)\end{array}$ \\
\hline Mean (SD) & $38.2(6.83)$ & $40.1(5.24)$ & & $40.0(5.32)$ \\
\hline Median [Min, Max] & $\begin{array}{l}36.9 \text { [26.3, } \\
46.9]\end{array}$ & $\begin{array}{l}39.9 \text { [25.1, } \\
52.3]\end{array}$ & & $\begin{array}{l}39.9 \text { [25.1, } \\
52.3]\end{array}$ \\
\hline ESR & & & 0.355 & \\
\hline Mean (SD) & $24.4(22.8)$ & $18.0(17.8)$ & & $18.3(18.0)$ \\
\hline Median [Min, Max] & $\begin{array}{l}21.5[5.00, \\
92.0]\end{array}$ & $\begin{array}{l}13.0[1.00, \\
98.0]\end{array}$ & & $\begin{array}{l}13.0[1.00, \\
98.0]\end{array}$ \\
\hline Blood transfusion & & & $<0.001$ & \\
\hline No & $6(50.0 \%)$ & $233(92.1 \%)$ & & $239(90.2 \%)$ \\
\hline Yes & $6(50.0 \%)$ & $20(7.9 \%)$ & & $26(9.8 \%)$ \\
\hline Sebum thickness & & & 0.015 & \\
\hline Mean (SD) & $10.7(3.66)$ & $7.69(3.69)$ & & $7.82(3.74)$ \\
\hline Median [Min, Max] & $\begin{array}{l}10.3[6.24, \\
17.0]\end{array}$ & $\begin{array}{l}6.85[2.10, \\
26.8]\end{array}$ & & $\begin{array}{l}6.94[2.10, \\
26.8]\end{array}$ \\
\hline Skin to lamina thickness & & & 0.763 & \\
\hline Mean (SD) & $46.2(11.2)$ & $47.2(9.80)$ & & $47.2(9.85)$ \\
\hline Median [Min, Max] & $\begin{array}{l}48.4[26.0 \\
60.3]\end{array}$ & $\begin{array}{l}46.6[3.37, \\
74.9]\end{array}$ & & $\begin{array}{l}46.6[3.37, \\
74.9]\end{array}$ \\
\hline
\end{tabular}

\subsection{Variables selection}

Univariate logistic regression analysis showed that, relative to the normal group, albumin, antibiotics, AT, blood transfusion, ESR, gender, glucose, $\mathrm{Hb}$, modic, number of screws, number of vertebral bodies spanned, sebum thickness, WBC were candidate predictors for the probability of SSI in lumbar Internal Fixation Surgery patients (all P<0. 05)(Table 3). 
Table 3

Univariate logistic regression of predictive factors for SSI in patients with lumbar Internal Fixation Surgery patients in training test.

\begin{tabular}{|llll|}
\hline Variables & OR & $95 \%$ Cl & P value \\
\hline Age & 1.015 & $0.988 \sim 1.045$ & 0.292 \\
\hline Albumin & 0.846 & $0.792 ~ 0.902$ & $<0.001^{*}$ \\
\hline Antibiotics & 2.493 & $1.336 \sim 4.655$ & 0.003 \\
\hline ASA & 0.873 & $0.430 \sim 1.734$ & 0.704 \\
\hline AT & 0.993 & $0.986 \sim 0.999$ & 0.046 \\
\hline Blood transfusion & 5.958 & $2.990 \sim 11.488$ & $<0.001^{*}$ \\
\hline Diabetes & 0.990 & $0.292 \sim 2.530$ & 0.985 \\
\hline ESR & 1.029 & $1.017 \sim 1.040$ & $<0.001^{*}$ \\
\hline Gender & 0.567 & $0.287 \sim 1.071$ & 0.088 \\
\hline Glucose & 1.133 & $1.012 \sim 1.247$ & 0.015 \\
\hline Hb & 0.954 & $0.940 \sim 0.968$ & $<0.001^{*}$ \\
\hline Modic & 13.142 & $8.171 \sim 22.804$ & $<0.001^{*}$ \\
\hline Number of screws & 1.313 & $1.145 \sim 1.508$ & $<0.001^{*}$ \\
\hline Number of vertebral bodies spanned & 1.384 & $1.112 \sim 1.719$ & 0.002 \\
\hline OP times & 1.003 & $0.997 \sim 1.008$ & 0.354 \\
\hline PLT & 1.000 & $0.997 \sim 1.002$ & 0.714 \\
\hline Sebum thickness & 1.120 & $1.075 \sim 1.169$ & $<0.001^{*}$ \\
\hline Skin to lamina thickness & 1.020 & $0.989 \sim 1.052$ & 0.195 \\
\hline WBC & 1.106 & $1.025 \sim 1.186$ & 0.006 \\
\hline Abbreviations: ASA: American Society of Anesthesiologists; OP times: operation times; AT: Anesthesia \\
\hline time; ESR: erythrocyte sedimentation rate; & & & \\
\hline *: Statistically significant difference. & & & \\
\hline
\end{tabular}

Besides, the multivariate logistic regression analysis is used to approximate the above candidate predictors and select the best subset of predictor variables, which is blood transfusion, glucose, $\mathrm{Hb}, \mathrm{ESR}$, modic, sebum thickness. (Table 4) 
Table 4

multivariate logistic regression analysis for SSI in patients after

Univariate logistic regression analysis in training test.

\begin{tabular}{|llll|}
\hline Variables & Odds ratio & $95 \% \mathrm{Cl}$ & P value \\
\hline Blood transfusion & 1.048 & $1.009 \sim 1.086$ & 0.013 \\
\hline ESR & 1.001 & $1.000 ~ 1.001$ & 0.044 \\
\hline Glucose & 1.009 & $1.004 \sim 1.013$ & $<0.001 *$ \\
\hline Hb & 0.999 & $0.9987 \sim 0.999$ & 0.027 \\
\hline Modic & 1.165 & $1.143 \sim 1.186$ & $<0.001 *$ \\
\hline Sebum thickness & 1.006 & $1.003 \sim 1.008$ & $<0.001^{*}$ \\
\hline *: Statistically significant difference. & \\
\hline
\end{tabular}

\subsection{Development of a Personalized Prediction Model.}

Following the result of Univariate and multivariate logistic regression analysis, A predictive model is developed and displayed as a nomogram(Figure 2), which includes the above-mentioned features.

\subsection{Plotting the ROC curve}

In addition, ROC curves were constructed and the AUC of the prediction model was calculated to be 0 . 976 , indicating that the model has a high recognition ability. (Figure 3 )

\subsection{Apparent performance of the SSI prediction nomogram}

Include in the train group and verification group, the calibration curve of the SSI prediction nomogram used to predict the probability of undergoing SSI in lumbar Internal Fixation Surgery patients showed good consistency in this retrospective study (Figure 4(a) and (b)). C index of 0.975 (95\% confidence interval: $0.964,0.987)$. The $\mathrm{C}$-index of the validation test was $0.981(95 \%$ confidence interval: 0. $957,1.005)$, indicating that the model had good predictive accuracy. The area under the curve (AUC) for training and validation tests were 0.976 and 0.982 , respectively (Figure 3(a) and 3(b)) implying a good discriminatory power of the model. In the SSI forecast nomogram, the apparent performance shows good forecasting ability.

\subsection{Clinical Use}

As shown in Figure 5, the constructed decision curve analysis serves as the assessment of the SSI risk nomogram. We can know from the decision curve analysis that when the threshold probability of patients and doctors is within a certain range, using this risk nomogram to predict the risk of SSI will be more 
beneficial than existing solutions, and this range is respectively $>1 \%$ And $<99 \%$. Within this range, based on the risk nomogram, the net benefit was comparable with several overlaps.

\section{Discussion}

Currently, the nomograms are widely used for cancer or others prognosis, due to these can simplify the statistical prediction model to a single numerical estimate of the probability of an event, such as death or recurrence, and the estimate is tailored to the individual patient's situation[8-11]. In this study, for the first time, the nomogram was used to evaluate the SSI rate of patients undergoing lumbar internal fixation surgery. In clinical practice, especially in surgical operations, poor healing of postoperative incisions often brings great distress to the attending physicians and patients[12,13]. Many studies have shown that Surgical site infections is closely related to many factors, such as Diabetes or blood sugar level, Serological indicators, inflammatory factors, antibiotics, nutritional status, obesity and etc. [14-18]. In our research, a novel tool was developed and verified for predicting SSI in lumbar Internal Fixation Surgery patients, using six readily available variables. By integrating imaging indicators, serological levels, and intraoperative conditions into the nomogram, the prediction of SSI in lumbar Internal Fixation Surgery patients is personalized and relatively accurate forecasting.

In risk factor analysis, SSI in lumbar Internal Fixation Surgery was associated with modic, glucose, Hb, ESR, blood transfusion, sebum thickness. The nomogram indicates that Lumbar disc mutation, High glucose level, Anemia, High ESR, Intraoperative blood transfusion, and Increased sebum thickness may be the critical factors in the risk of SSI in lumbar Internal Fixation Surgery.

Diabetes has always been the focus of surgeons' attention, and it is also an important factor related to surgery site infection[19-21]. Hyperglycemia affects various pathways of the immune system, leading to decreased phagocytosis and chemotaxis of neutrophils and monocytes, resulting in increased neutrophil apoptosis and decreased monocyte antigen delivery capacity, respectively[22, 23]. Thus, Perioperative blood glucose management is very important for the incision healing of patients after lumbar spine surgery, and the preoperative blood glucose level can also be used as an evaluation indicator for the postoperative incision healing. Low back pain (LBP) is the one of the most disabling conditions worldwide, and is usually associated with modic changes which could be foci of chronic subclinical infection and not mere markers of degeneration, as initially described, by a retrospective analysis[24]. It is well known that the modic1 stage is the inflammatory phase, which is related to the knowledge of postoperative wound infection, due to the localized action of proinflammatory mediators, and more recently low-grade bacterial infection[25]. In our multivariate regression analysis, modic changes have strong statistical significance $(p<0.001)$.

In our prediction model, the preoperative hemoglobin value is closely related to the incidence of SSI. In other words, the lower the hemoglobin, the higher the probability of SSI. In existing studies, it has been found that anemia is one of the key factors that cause SSI[26, 27]. In support of this finding, a retrospective study has reported evidence that supports that the change in hemoglobin value is a useful 
indicator of the occurrence of related complications after spinal surgery[28]. The healing of the surgical incision is closely related to the blood oxygen saturation of the incision microenvironment, due to the increased demand for reparative processes such as cell proliferation, bacterial defence, angiogenesis and collagen synthesis[29]. Therefore, adequate tissue perfusion and oxygenation is an absolute pre-requisite for a successful repair, and the content of hemoglobin with the ability to carry oxygen determines the prognosis of the incision. Besides, erythrocyte sedimentation rate (ESR), refers to the sedimentation speed of red blood cells under certain conditions. The ESR of healthy people fluctuates in a narrow range, many pathological conditions can significantly increase the ESR and the ESR is the result of the interaction of many factors. Previous studies on surgical procedures have shown that ESR is considered a useful marker for early diagnosis of SSI[4]. In addition, intraoperative blood transfusion is also statistically significant for incision healing. According to a retrospective cohort study, one of the risk factors for postoperative infection in spinal surgery may be intraoperative allogeneic red blood cell infusion[30]. A research had thinks that whether patients undergoing lumbar spine surgery receive allogeneic blood transfusion during or after surgery, the risk of infection at the surgical site, urinary tract infection and overall postoperative infection will increase, except that the risk of pneumonia is not increased[31]. Therefore, based on the current research, whether blood transfusion is required during the perioperative period of lumbar spine surgery, we should follow the blood transfusion principles or guidelines[32].

In lumbar spine surgery, obesity or BMI is mostly a risk factor for incisions infection after lumbar spine surgery, Since BMI may not reflect the composition of specific parts of the body, in a prospective study, Emily Waisbren and others used percent body fat $(\% \mathrm{BF})($ Body fat $\%=(1.20 \times \mathrm{BMI})+(0.23 \times$ age $)-(10.8$ $\times$ gender) -5.4$)$ as an independent risk factor, and think that unlike the traditional definition of obesity, this type of obesity defined by \%BF is associated with a 5 -fold increase in the risk of SSI, and this risk also increases with the increase of \%BF, which is more sensitive and accurate than BMI SSI risk measurement, but further research is needed to better understand this relationship[33, 34]. In our measurement, the thickness of the sebum in the lumbar spine surgery area is taken as the measurement value of the specific part, this has a better guiding significance for the infection of the incision at the specific surgical site.

In our study, a new predictive model was established to evaluate the probability of SSI after lumbar internal fixation, this is both benefit for spine surgeons and patients after lumbar spine surgery. Before this, there was no comprehensive evaluation system that included imaging, serology, etc. We have carried out internal verification in the existing data, and demonstrated good clinical practicability and effectiveness in both the experimental group and the verification group. Besides, the internal validation of this study shows excellent discriminative and corrective power, especially the interval validation of our satisfactory C-index (0.981) proves that the prediction model can be broadly and accurately applied to the vast majority of cases.

\section{Limitations}


Our current study also suffers from the following shortcomings. The predictive factors analysis did not include all potential factors affecting the probability of SSI. Some of the potential influences on the probability of SSI, such as number of screws, number of vertebral bodies spanned, etc., were not fully understood. Although our prediction model proved to be robust in internal validation, it lacks externally validated, and thus may be biased if applied to other SSI patients in other regions. These are precisely the issues that need to be addressed in our subsequent study.

\section{Conclusion}

Clinicians can use a new nomogram to assess the risk of the surgery site infection rate of lumbar Internal Fixation Surgery patients, which is based on a predictive model developed by current research, so as to provide necessary early intervention measures and reasonable postoperative guidance. However, to determine whether intervention of risk factors can effectively reduce the infection rate of the surgical site in patients undergoing lumbar internal fixation surgery, the nomogram still needs extensive external verification.

\section{Abbreviations}

\section{SSI}

surgery site infection

$\mathrm{Cl}$

Confidence interval

AUC

Area under the curve

BMI

body mass index.

\section{Declarations}

\section{Ethics approval and consent to participate}

We confirm that all subjects and /or their legal guardians provided written informed consent for participation in this study. Written informed consent was obtained from the patient for publication of this research and any accompanying images. Prior approval of the study was obtained from the institutional ethical review board of The First Affiliated Hospital of Guangxi Medical University (No.2021(KY-E-223)). We have determined that all methods are carried out in accordance with the relevant guidelines and regulations.

\section{Consent for publication}

Not applicable. 


\section{Availability of data and materials}

The datasets generated during and analyzed during the current study are not publicly available due to the data involves patient privacy, we do not publish it publicly, but are available from the corresponding author on reasonable request.

\section{Competing interests}

The authors declare that they have no financial or other conflicts or interest in relation to this research and its publication.

\section{Funding}

This study was supported by the National Natural Science Foundation of China, Grant/Award number: 81860393.

\section{Authors' contributions}

All authors read and approved the final manuscript.

Tianyou Chen and Zide Zhang: Conceptualization, Methodology, Software. Tuo Liang, Tianyou Chen and Jiarui Chen: Data curation, Writing- Original draft preparation. Jie Jiang, Tianyou Chen and Hao Li: Visualization, Investigation. Chong Liu and Xinli Zhan: Supervision. Hao Guo, Wuhua Chen and Zhen Ye: Software, Validation. Yuanlin Yao and Shian Liao: Writing- Reviewing and Editing.

\section{Acknowledgments}

We are grateful to Dr. Xinli Zhan (Guangxi Medical University) for his kindly assistance in all stages of the present study. This study was supported by the National Natural Science Foundation of China, Grant/Award number: 81860393.

\section{References}

1. Owens CD, Stoessel K (2008) Surgical site infections: epidemiology, microbiology and prevention. J Hosp Infect 70 Suppl 2:3-10. doi: 10.1016/s0195-6701(08)60017-1

2. Peng XQ, Sun CG, Fei ZG, Zhou QJ (2019) Risk Factors for Surgical Site Infection After Spinal Surgery: A Systematic Review and Meta-Analysis Based on Twenty-Seven Studies. World Neurosurg 123:e318-e329. doi: 10.1016/j.wneu.2018.11.158

3. Zhou J, Wang R, Huo X, Xiong W, Kang L, Xue Y (2020) Incidence of Surgical Site Infection After Spine Surgery: A Systematic Review and Meta-analysis. Spine (Phila Pa 1976) 45:208-216. doi: $10.1097 /$ brs. 0000000000003218

4. Zheng S, Wang Z, Qin S, Chen JT (2020) Usefulness of inflammatory markers and clinical manifestation for an earlier method to diagnosis surgical site infection after spinal surgery. Int 
Orthop 44:2211-2219. doi: 10.1007/s00264-020-04567-0

5. Ogihara S, Yamazaki T, Shiibashi M, Chikuda H, Maruyama T, Miyoshi K, Inanami H, Oshima Y, Azuma S, Kawamura N, Yamakawa K, Hara N, Morii J, Okazaki R, Takeshita Y, Tanaka S, Saita K (2021) Risk factors for deep surgical site infection following posterior instrumented fusion for degenerative diseases in the thoracic and/or lumbar spine: a multicenter, observational cohort study of 2913 consecutive cases. Eur Spine J 30:1756-1764. doi: 10.1007/s00586-020-06609-y

6. Ma R, He J, Xu B, Zhao C, Zhang Y, Li X, Sun S, Zhang Q (2020) Nomogram prediction of surgical site infection of HIV-infected patients following orthopedic surgery: a retrospective study. BMC Infect Dis 20:896. doi: 10.1186/s12879-020-05613-3

7. Borchardt RA, Tzizik D (2018) Update on surgical site infections: The new CDC guidelines. Jaapa 31:52-54. doi: 10.1097/01.Jaa.0000531052.82007.42

8. Iasonos A, Schrag D, Raj GV, Panageas KS (2008) How to build and interpret a nomogram for cancer prognosis. J Clin Oncol 26:1364-1370. doi: 10.1200/jco.2007.12.9791

9. Balachandran VP, Gonen M, Smith JJ, DeMatteo RP (2015) Nomograms in oncology: more than meets the eye. Lancet Oncol 16:e173-180. doi: 10.1016/s1470-2045(14)71116-7

10. Duan F, Song C, Ma Y, Jiang K, Xu F, Bi X, Huang J, Hong R, Huang Z, Lu Q, Yuan Z, Wang S, Xia W (2021) Establishment of Prognostic Nomograms for Predicting the Survival of HR-Positive, HER2Negative Metastatic Breast Cancer Patients Treated with Everolimus. Drug Des Devel Ther 15:34633473. doi: $10.2147 /$ dddt.S314723

11. Raghav K, Hwang H, Jácome AA, Bhang E, Willett A, Huey RW, Dhillon NP, Modha J, Smaglo B, Matamoros A, Jr., Estrella JS, Jao J, Overman MJ, Wang X, Greco FA, Loree JM, Varadhachary GR (2021) Development and Validation of a Novel Nomogram for Individualized Prediction of Survival in Cancer of Unknown Primary. Clin Cancer Res 27:3414-3421. doi: 10.1158/1078-0432.Ccr-20-4117

12. Young PY, Khadaroo RG (2014) Surgical site infections. Surg Clin North Am 94:1245-1264. doi: 10.1016/j.suc.2014.08.008

13. Anderson DJ (2011) Surgical site infections. Infect Dis Clin North Am 25:135-153. doi: 10.1016/j.idc.2010.11.004

14. Wukich DK, McMillen RL, Lowery NJ, Frykberg RG (2011) Surgical site infections after foot and ankle surgery: a comparison of patients with and without diabetes. Diabetes Care 34:2211-2213. doi: $10.2337 / \mathrm{dc} 11-0846$

15. Aldrich AL, Heim CE, Shi W, Fallet RW, Duan B, Kielian T (2020) TLR2 and caspase-1 signaling are critical for bacterial containment but not clearance during craniotomy-associated biofilm infection. $J$ Neuroinflammation 17:114. doi: 10.1186/s12974-020-01793-6

16. Johnson-Jahangir H, Agrawal N (2019) Perioperative Antibiotic Use in Cutaneous Surgery. Dermatol Clin 37:329-340. doi: 10.1016/j.det.2019.03.003

17. Tsantes AG, Papadopoulos DV, Lytras T, Tsantes AE, Mavrogenis AF, Korompilias AV, Gelalis ID, Tsantes CG, Bonovas S (2019) Association of malnutrition with periprosthetic joint and surgical site 
infections after total joint arthroplasty: a systematic review and meta-analysis. J Hosp Infect 103:6977. doi: 10.1016/j.jhin.2019.04.020

18. Yuan K, Chen HL (2013) Obesity and surgical site infections risk in orthopedics: a meta-analysis. Int J Surg 11:383-388. doi: 10.1016/j.ijsu.2013.02.018

19. Bellusse GC, Ribeiro JC, de Freitas ICM, Galvão CM (2020) Effect of perioperative hyperglycemia on surgical site infection in abdominal surgery: A prospective cohort study. Am J Infect Control 48:781785. doi: 10.1016/j.ajic.2019.11.009

20. Pennington Z, Lubelski D, Westbroek EM, Ahmed AK, Passias PG, Sciubba DM (2020) Persistent Postoperative Hyperglycemia as a Risk Factor for Operative Treatment of Deep Wound Infection After Spine Surgery. Neurosurgery 87:211-219. doi: 10.1093/neuros/nyz405

21. Upadhyaya S, Lopez WY, Goh BC, Chen AF, Blucher JA, Beck A, Kang JD, Schoenfeld AJ (2020) Postoperative hyperglycemia and its association with surgical site infection after instrumented spinal fusion. Clin Neurol Neurosurg 197:106100. doi: 10.1016/j.clineuro.2020.106100

22. Blondet JJ, Beilman GJ (2007) Glycemic control and prevention of perioperative infection. Curr Opin Crit Care 13:421-427. doi: 10.1097/MCC.0b013e32826388a1

23. Turina M, Miller FN, Tucker CF, Polk HC (2006) Short-term hyperglycemia in surgical patients and a study of related cellular mechanisms. Ann Surg 243:845-851; discussion 851-843. doi: 10.1097/01.sla.0000220041.68156.67

24. Pradip IA, Dilip Chand Raja S, Rajasekaran S, Sri Vijayanand KS, Shetty AP, Kanna RM, Thippeswamy PB (2021) Presence of preoperative Modic changes and severity of endplate damage score are independent risk factors for developing postoperative surgical site infection: a retrospective casecontrol study of 1124 patients. Eur Spine J 30:1732-1743. doi: 10.1007/s00586-020-06581-7

25. Rajasekaran S, Soundararajan DCR, Nayagam SM, Tangavel C, Raveendran M, Thippeswamy PB, Djuric N, Anand SV, Shetty AP, Kanna RM (2021) "Modic changes are associated with activation of intense inflammatory and host defense response pathways - molecular insights from proteomic analysis of human intervertebral discs". Spine J. doi: 10.1016/j.spinee.2021.07.003

26. Almeida ND, Lee R, Bestourous D, Klein AL, Parekh NR, Sack K, Sherman JH (2020) Perioperative Complications Associated with Severity of Anemia in Geriatric Patients Undergoing Spinal Procedures. World Neurosurg 135:e307-e320. doi: 10.1016/j.wneu.2019.11.159

27. Pollock JR, Doan MK, Moore ML, Hassebrock JD, Makovicka JL, Deckey DG, Kile TA, Patel KA (2021) 30-Day Outcomes for Total Ankle Arthroplasty in Patients With Anemia. Foot Ankle Int:10711007211017512. doi: 10.1177/10711007211017512

28. Purvis TE, Goodwin CR, Molina CA, Frank SM, Sciubba DM (2018) Percentage change in hemoglobin level and morbidity in spine surgery patients. J Neurosurg Spine 28:345-351. doi: 10.3171/2017.7.Spine17301

29. Schreml S, Szeimies RM, Prantl L, Karrer S, Landthaler M, Babilas P (2010) Oxygen in acute and chronic wound healing. Br J Dermatol 163:257-268. doi: 10.1111/j.1365-2133.2010.09804.x 
30. Fisahn C, Jeyamohan S, Norvell DC, Tubbs RS, Moisi M, Chapman JR, Page J, Oskouian RJ (2017) Association Between Allogeneic Blood Transfusion and Postoperative Infection in Major Spine Surgery. Clin Spine Surg 30:E988-e992. doi: 10.1097/bsd.0000000000000539

31. Janssen SJ, Braun Y, Wood KB, Cha TD, Schwab JH (2015) Allogeneic blood transfusions and postoperative infections after lumbar spine surgery. Spine J 15:901-909. doi:

10.1016/j.spinee.2015.02.010

32. Barrie U, Youssef CA, Pernik MN, Adeyemo E, Elguindy M, Johnson ZD, Ahmadieh TYE, Akbik OS, Bagley CA, Aoun SG (2021) Transfusion guidelines in adult spine surgery: a systematic review and critical summary of currently available evidence. Spine J. doi: 10.1016/j.spinee.2021.07.018

33. Taree A, Mikhail CM, Markowitz J, Ranson WA, Choi B, Schwartz JT, Cho SK (2021) Risk Factors for 30- and 90-Day Readmissions Due To Surgical Site Infection Following Posterior Lumbar Fusion. Clin Spine Surg 34:E216-e222. doi: 10.1097/bsd.0000000000001095

34. Gupta VK, Zhou Y, Manson JF, Watt JP (2021) Radiographic spine adipose index: an independent risk factor for deep surgical site infection after posterior instrumented lumbar fusion. Spine J 21:17111717. doi: 10.1016/j.spinee.2021.04.005

\section{Figures}




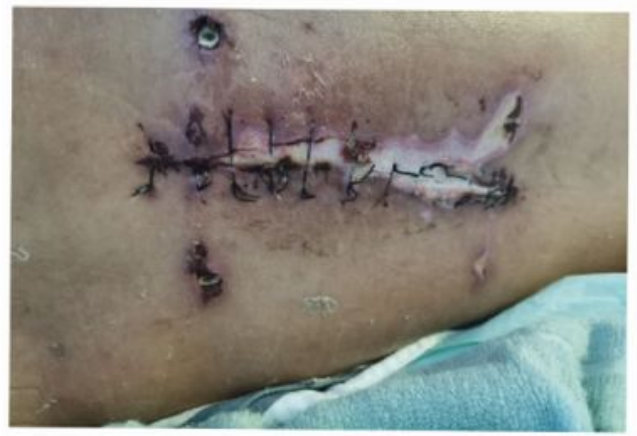

(a)

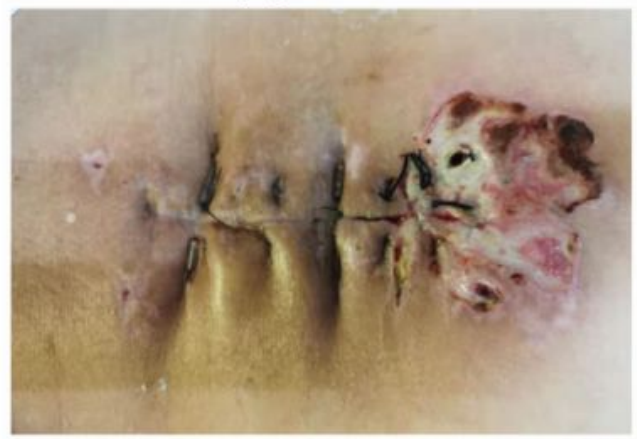

(c)

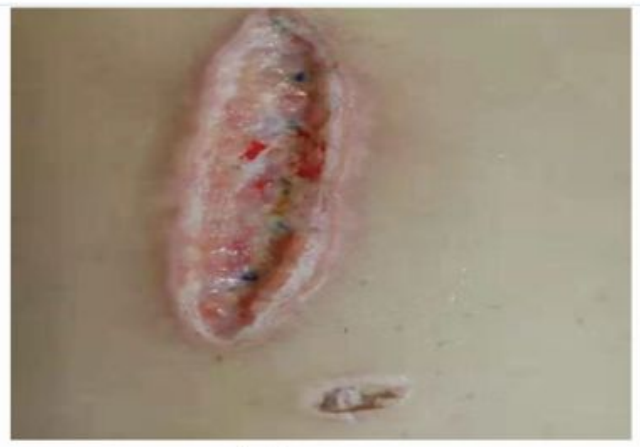

(e)

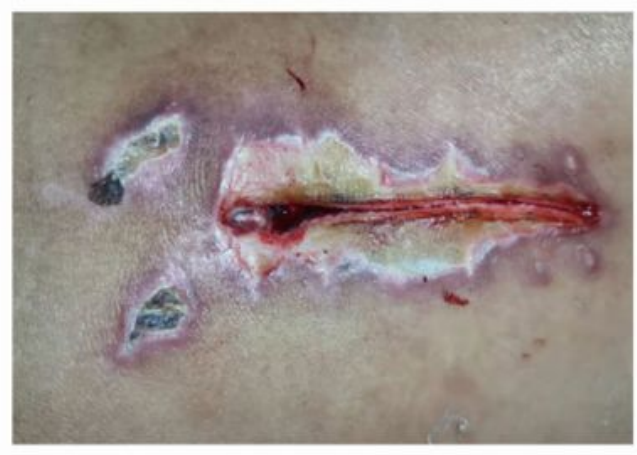

$(g)$

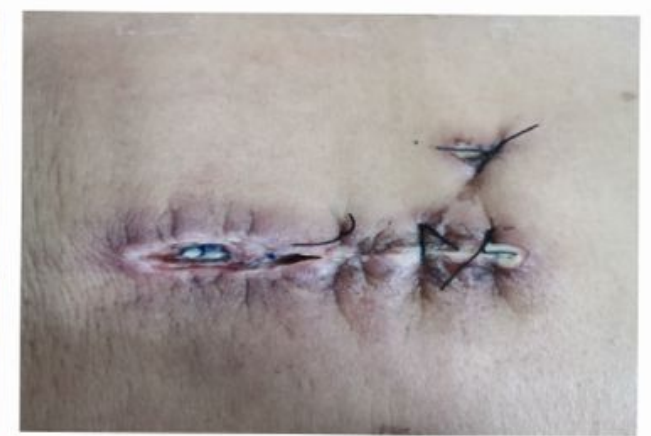

(b)

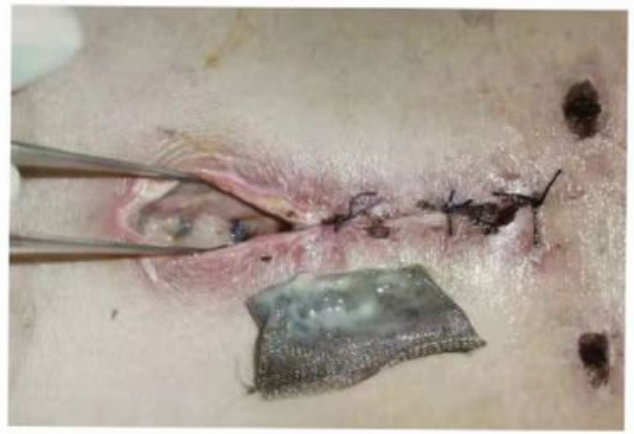

(d)

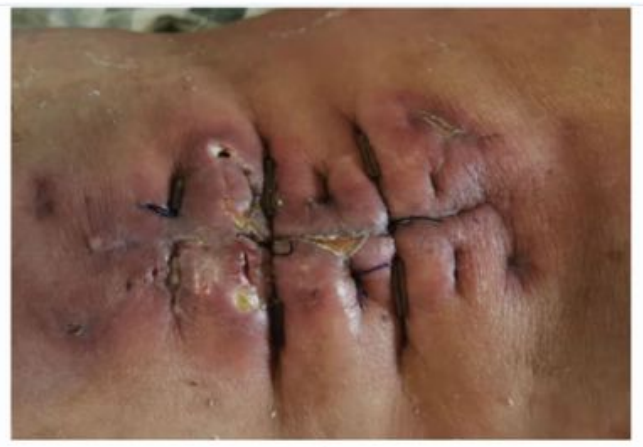

(f)

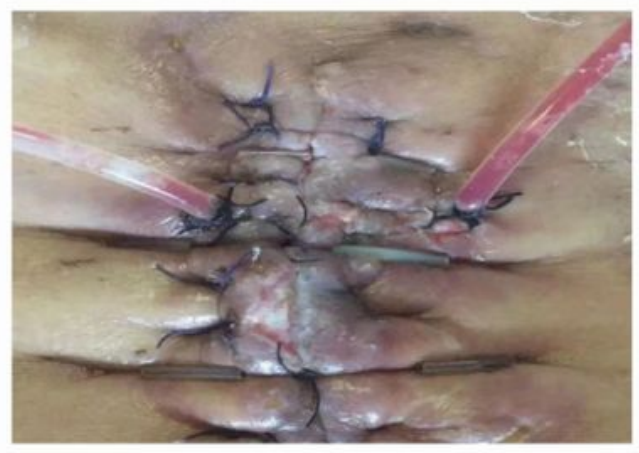

(h)

\section{Figure 1}

Typical cases of surgery site infection after lumbar internal fixation surgery. 
Modic 2

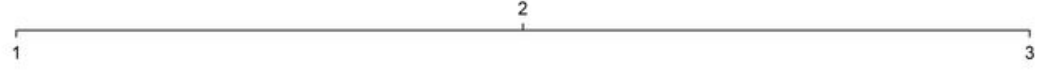

ESR

$$
\begin{array}{lllllll}
0^{\prime} & 20 & 40 & 60 & 80 & 110
\end{array}
$$

$\mathrm{Hb}$

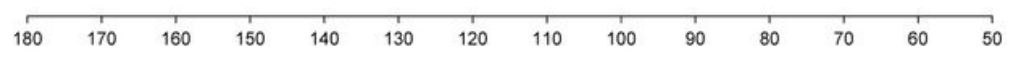

Blood_transfusion Yes

Sebum_thickness
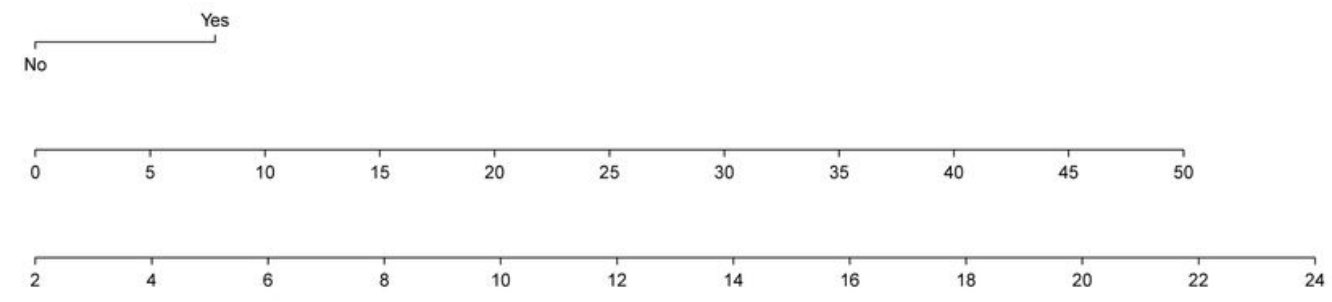

Total Points

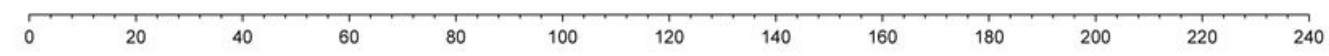

SSI Probability

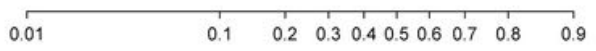

Figure 2

Construction of a nomogram for surgery site infection after the lumbar internal fixation surgery.

(a) Training test

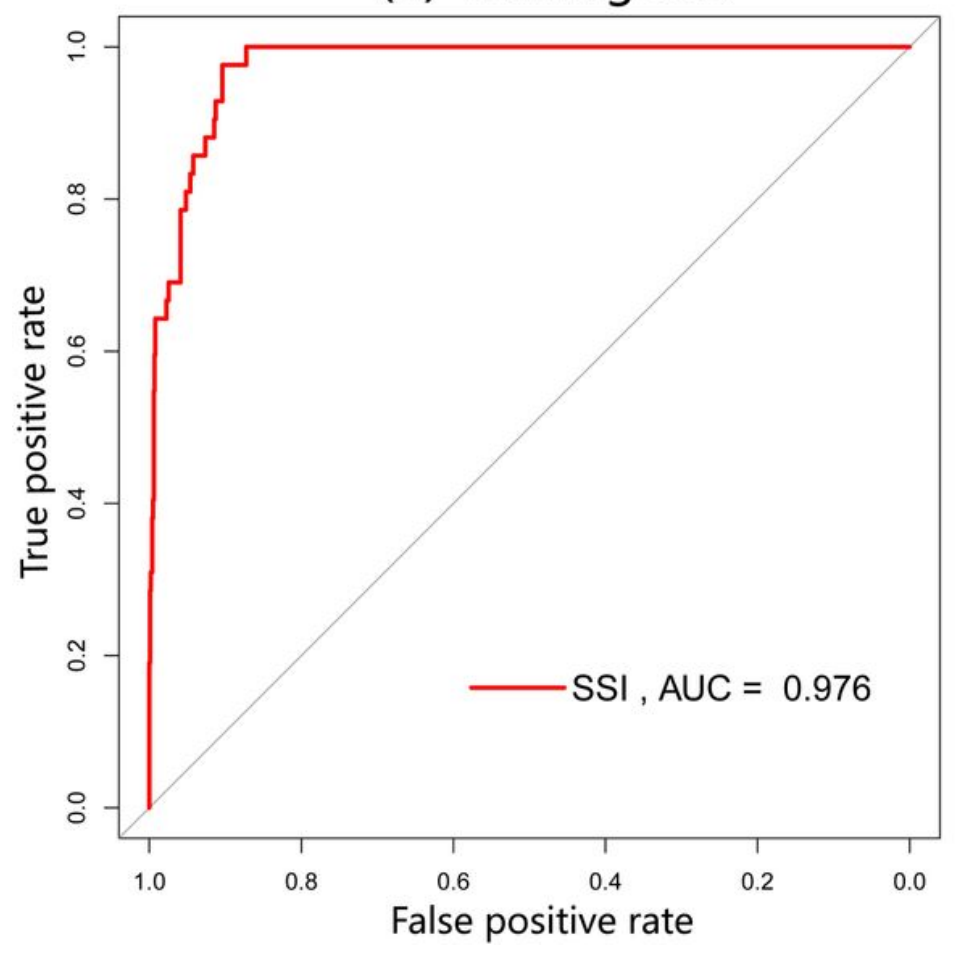

(b) Validation test

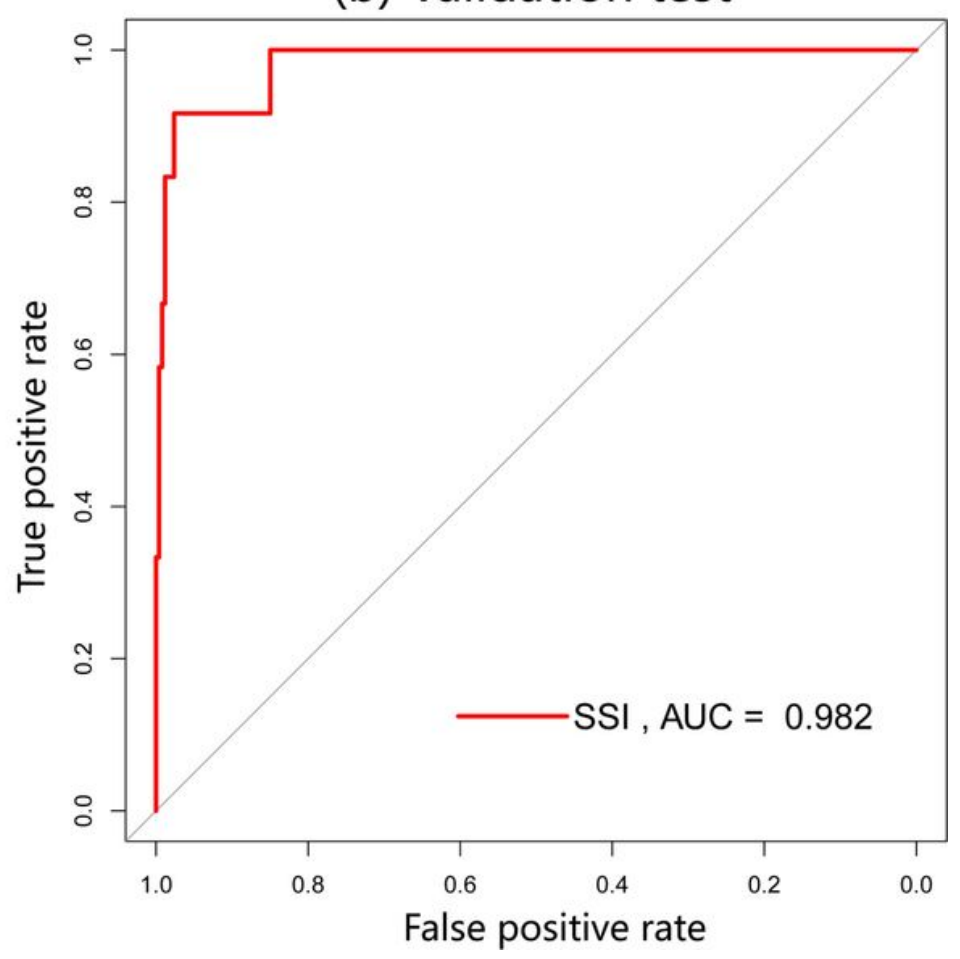

Figure 3 
ROC curve analysis for training and validation tests. (a) Training test. (b) Validation test. AUC: area under curve.

(a) Training test

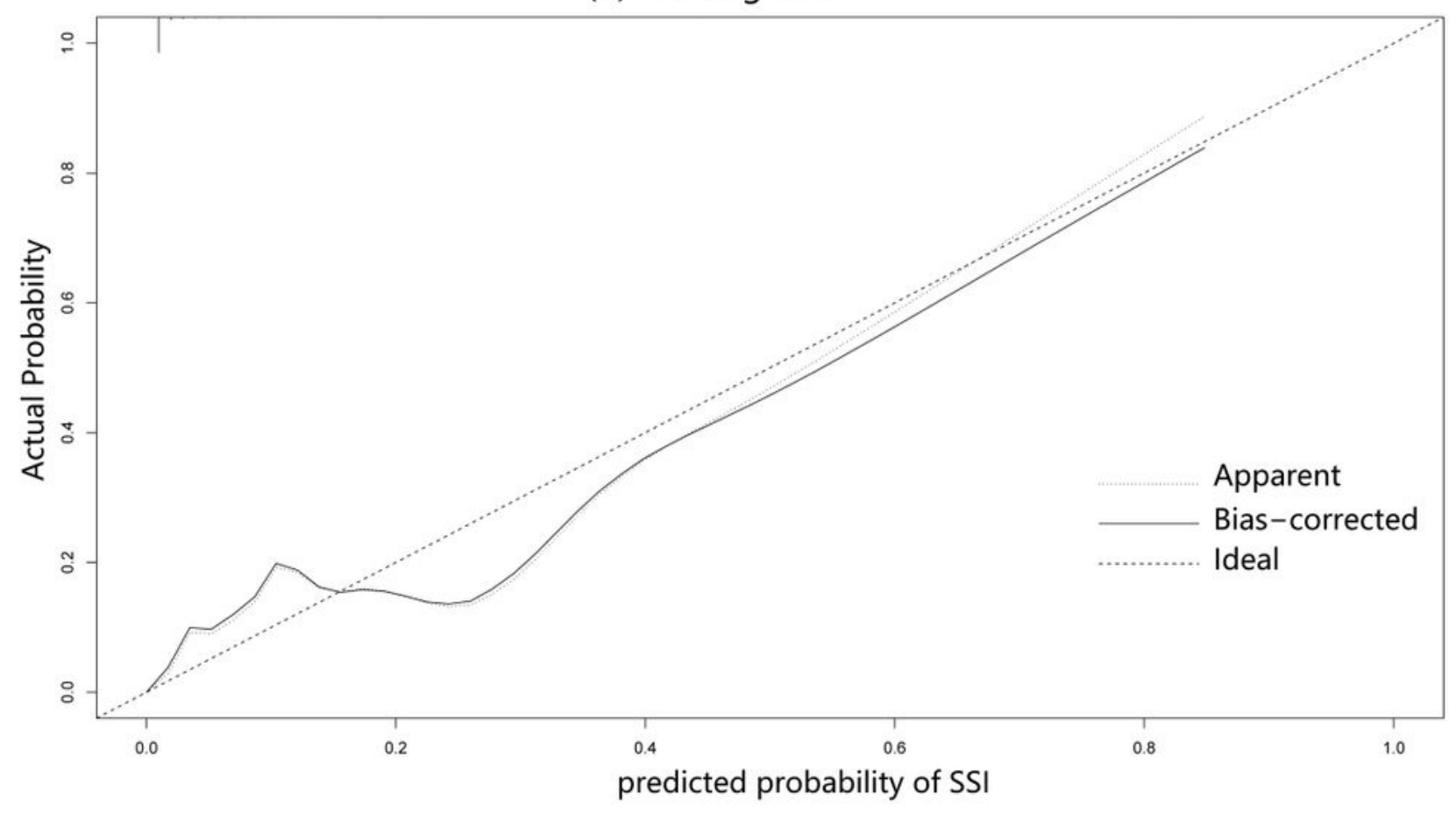

(b) Validation test

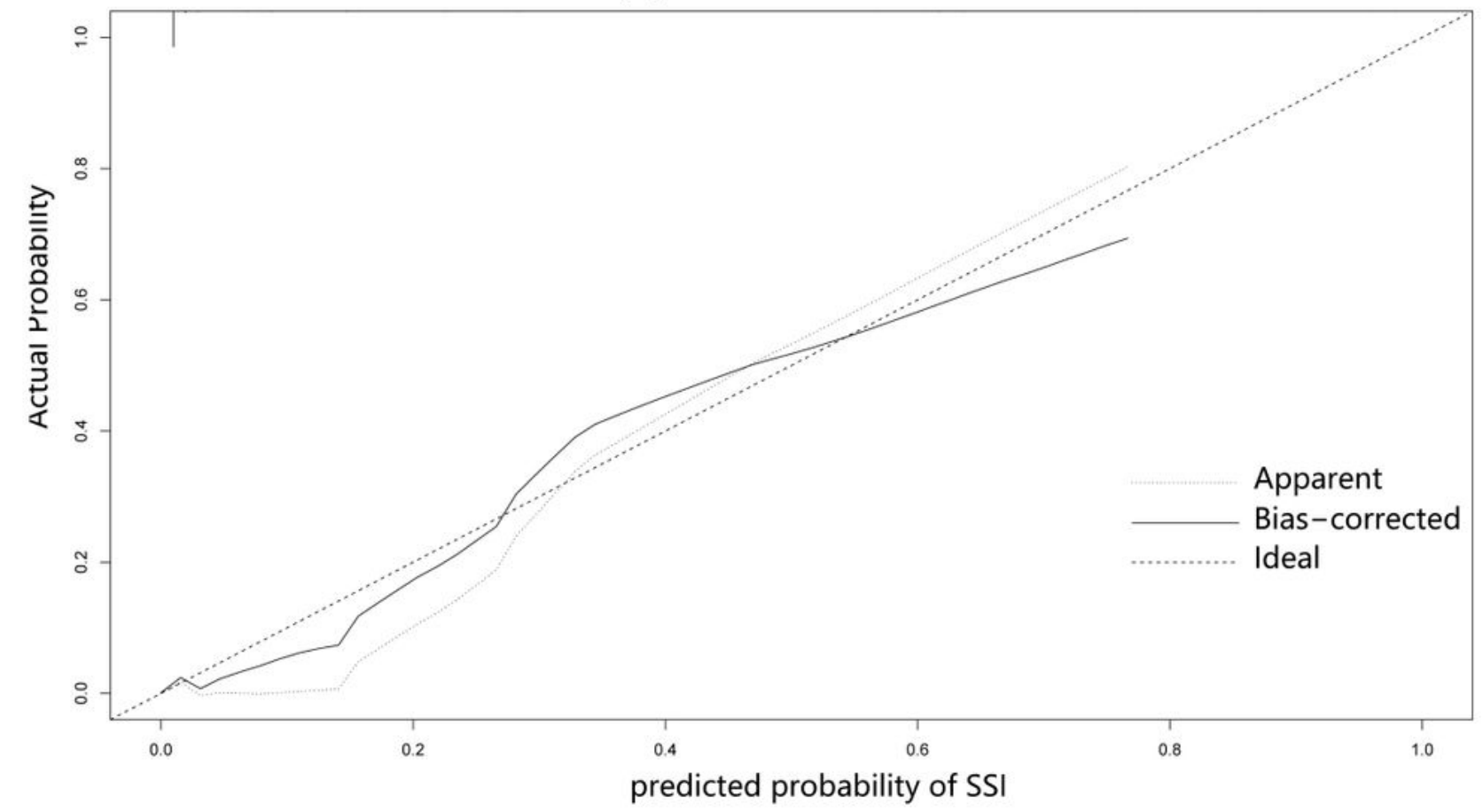

Figure 4

Calibration curves for predicting the risk profile of surgery site infection in the cohort for training and validation tests. (a) Training test. (b) Validation test. The x-axis represents the predicted risk of surgery 
site infection. The y-axis represents the actual diagnosis of surgery site infection. The diagonal dashed line represents an ideal perfect prediction model. Solid lines represent the performance of the nomogram, where closer proximity to diagonally dashed lines represents better prediction.

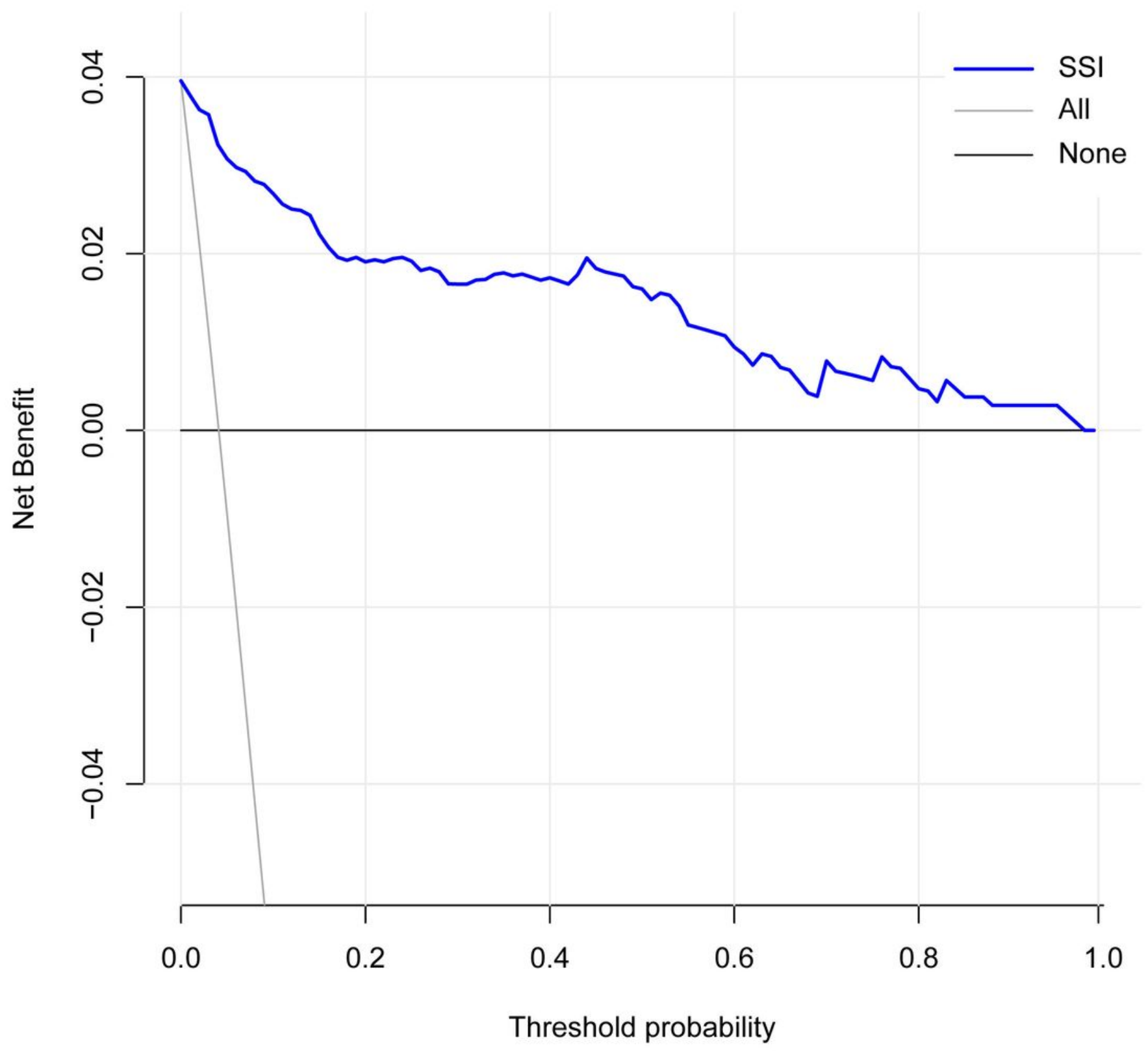

Figure 5

Decision curve analysis of the SSI prediction nomogram. Note: y-axis measures the net benefit. The dashed line indicates SSI prediction nomogram. The thin solid line indices assumption that all patients underwent SSI. Thin thick solid line represents the hypothesis that no patients underwent SSI. The decision curve showed that if the threshold probability of a patient and a doctor is $>1 \%$ and $<99 \%$, 
respectively, using this SSI prediction nomogram in the currstudy to predict SSI risk adds more benefit than the intervention-all-patients scheme or the intervention-none. 